\section{DEVELOPMENT OF BOTANICAL INVESTIGATIONS AT ROTHAMSTED}

\begin{abstract}
A T the meeting of the Linnean Society on June 24, A Sir John Russell and three of his staff outlined the history of the botanical work at Rothamsted Experimental Station since it was founded one hundred years ago.

In a rapid survey Sir John Russell showed how the association of Sir John Lawes-an essentially practical man-and Sir Henry Gilbert-a research worker with a genius for detail-led to the establishment of agricultural science on a firm basis in Great Britain. At the beginning the chemical aspect of crop growth was the only one considered, and much of the early work was determined by the controversy on the nitrogen nutrition of plants. Liebig emphasized, quite rightly, the value of mineral fertilizers, but maintained that the use of nitrogenous manures was unnecessary, as the plants obtained most of their nitrogen from the air. Lawes and Gilbert disagreed, and proved the value of nitrogenous fertilizers on the wheat plots on Broadbalk Field, obtaining striking increases in height and yield with progressively greater applications of ammonium sulphate. The problem of the source of the nitrogenous compounds in the soil was worked on by Prof. Robert Warington who, though primarily a chemist, diagnosed the activity of two forms of soil organism, one of which converted ammonia into nitrite, and the other transformed the nitrite into nitrate, thus completing the work of nitrification. He was not, how ever, able to isolate the two forms of bacteria concerned.
\end{abstract}

From 1856 onwards the botanical side began to emerge, primarily from studies of changes in the herbage of grassland induced by differences in manuring when the same treatment was continued year after year. Also, close observation was kept on the weeds' in the arable crops, showing differences related to the varied manuring. Until the death of the founders in 1901 the botanical side retained this status of purely observational work on the fields.

With the coming of Sir Daniel Hall as director, the laboratory side of the work began to extend. There was a fuller recognition that plants are living things and therefore no two are quite alike, either in their form, development or response to similar conditions of nutrition or environment. Also it was recognized that no two areas of soil in the same field are absolutely identical, and that consequently it is not possible to adopt the same technicue in dealing with plants as with chemical substances with their fixed reaction to any particular set of conditions. The recognition of these basal facts led to the gradual development of various departments concerned with different aspects of agricultural science. On the physical side it was realized that soil is not simply a supplier of food, but is a source of water and also provides a definite environment, specially in connexion with the supply of air to, the roots of plants. Statistical methods were applied by Prof. R. A. Fisher to the lay-out of plot experiments, whereby smaller areas could be utilized, more treatments dealt with in a single experiment, and more accurate results obtained. On the bacteriological side the effects of partial sterilization on the soil microflora were worked out and, more recently, practical methods have been developed for inoculating lucerne seed with the appropriate nodule organisms

In the earlier days attention had been focused on the importance of the 'major' elements, as nitrogen, potassium and phosphorus, in plant nutrition. Since 1906 the relation between 'minor' elements and plant growth has been under continuous consideration by Dr. W. E. Brenchley and her colleagues. The term 'minor' element is used to indicate those elements of which extremely small amounts are sufficient to influence the plant, either beneficially or harmfully. It in no sense indicates that these elements are minor in importance. In fact biologists and agriculturists alike are becoming alive to the fact that these elements are of the greatest importance in the metabolism of the plant, and in this connexion they are attracting attention much as vitamins have done in the economy of animal life. The complex chemical composition of soil renders it a very difficult medium on which to test the effect of minor elements on plants, as no real control can be exercised on the elements available to the roots. Such control is afforded by the nutrient solution method, and all the initial research has been carried out in this way.

Attention was first directed to a group of five minor elements already associated with plant growth in one way or another-copper, manganese, zinc, arsenic and boron, tested over a wide range of concentrations. Toxicity was easily shown-copper and arsenic being about ten times more deadly in the stronger concentrations than any of the others, manganese and boron being required in relatively. large amounts to be lethal. Further work with copper, nickel and cobalt showed the varying response of individuals to concentrations on the border line of toxicity. In the presence of solid particles such as quartz, sand, or soil the poisonous action is greatly reduced. Consequently, plants growing in soil may be able to make normal growth in the presence of an amount of a poisonous substance which would kill, or at least seriously damage, a similar plant in nutrient solution.

Stimulation with minute traces of elements was far more difficult to demonstrate, though some indication was obtained. Following up an accidental clue obtained in 1921 , Dr. K. Warington proved conclusively that in the absence of a trace of boron, growth of broad beans was completely checked, owing to atrophy of the meristematic points and subsequent breakdown of the tissues. The growing points of stems and roots, the flower buds and also the meristematic tissues of the nodules on the roots are all affected. Many other plants were also shown to require a trace of boron, and the work and literature on the subject has become very extensive. Various obscure plant diseases, hitherto classed vaguely as 'physiological', are now known to be due to boron deficiency. Heart rot of sugar beet, raan of turnips, topsiekte of tobacco, and other crop diseases are curable or prevented by the addition of about 12-20 lb. per acre of borax.

The fertilizer Chilean nitrate contains a number of minor elements, of which boron and iodine are the most prominent. The quantity of boron is adequate for the needs of plants, but so far it has not been possible to demonstrate any agricultural value of the iodine, though it is still possible that the feeding value of the crops may be improved by the absorbed iodine. Molybdenum is also present, and claims have been made elsewhere that it is essential 
for tomatoes. The results so far obtained at Rothamsted have been variable, though it is possible that molybdenum may hasten the ripening of tomatoes.

The more work that is done on minor elements the more complex the problem becomes. The cumula. tive evidence seems to suggest that deficiency symptoms are not always entirely the result of an inadequate supply of some critical element, but may also be bound up with other factors at present not fully recognized. Future work will doubtless have to be concerned with these factors as well as with the direct influence of minor elements on plant growth.

The recent bacteriological work at Rothamsted under Dr. H. G. Thornton has largely been related to the nodules produced on leguminous plants. It is well known that these nodule-forming bacteria fall into groups that are in general specific to certain groups of species or genera among their host plants. The bacteria are further subdivided into,strains within each host-specific group. If a number of bacterial cultures are isolated from nodules on a single host species, they are found to vary very much in the benefit they confer on their host plant through nitrogen fixation. At one end of the range there are often to be found strains that are largely ineffective in this respect-scarcely increasing the nitrogen content of their host plant. Such ineffective strains are particularly noticeable among the nodule bacteria of clover and of peas and beans. A survey is now being made of the distribution of ineffective clover nodule bacteria in Great Britain. These are found to be particularly abundant in the poor sheep pastures of hill districts in Wales, the north of England and Scotland. The study of these strains has the improvement of the clover growth in such pastures as its ultimate object.

Anatomical study of the nodules produced by ineffective strains shows that these have a much smaller content of infected tissue than do effective nodules. In addition, the tissue disintegration and dissolution of the contained bacteria, which eventually occur in all nodules, take place much earlier in those produced by ineffective strains. If these factors are taken into consideration the amount of nitrogen fixed by a unit volume of bacterial tissue in a given time is the same for 'effective' and 'ineffective' strains. The latter are ineffective because they do not grow so well or last so long in the nodule as do the effective strains. It has been found that individual plants vary greatly in their response to the nodule bacteria. In a few plants, bacteria belonging to a normally ineffective strain can produce nodules of normal size and can benefit the plant. The converse can happen with a normally effective strain of the bacteria. There is some evidence that this variation in the response of the host legume is hereditary. If this is confirmed, it raises the hope that varieties of clover can be developed giving an effective response to infection even by a normally ineffective bacterial strain.

It may also be possible to mitigate the effects of a population of ineffective strains of nodule bacteria in the soil by supplying effective strains through seed 'inoculation'. Here, however, a difficulty arises owing to the acute competition that takes place in the root surroundings between different strains of nodule bacteria. Strains that compete successfully with others are those having a high initial multiplication rate in the soil. Strains have now been found that combine this high multiplication-rate with effectiveness towards their host plant. Such strains can compete successfully with ineffective strains in the soil and should thus be useful for the purpose of 'inoculation'.

Mr. F. C. Bawden proceeded to describe the investigations that have been made into the precise nature of those mysterious entities known as viruses. Viruses can conveniently be defined as obligately parasitic pathogens, too small to be resolved by ordinary microscopical methods. Their scientific study dates back to 1892 when Iwanowski, a Russian botanist, demonstrated that tobacco mosaic is a virus disease.

During the next forty years the number of recog. nized virus diseases increased steadily, and considerable progress was made in symptomatology and in discovering the means whereby viruses are transmitted, but little or no information was gained about their nature. They were generally believed to be the smallest living organisms, essentially similar to bacteria, though with the unfortunate properties of being invisible and unable to grow in culture media. During the last seven years, however, specific proteins have been isolated from plants infected separ. ately with several different viruses, and all the avail. able information suggests that these proteins are the viruses themselves. The size of the protein particles varies with different viruses, but all so far examined have particles with weights equivalent to molecular weights in excess of a million.

Tobacco mosaic virus was the first to be isolated, and is now recognized as a liquid crystalline nucleoprotein, in which X-ray diffraction has revealed a regularity of structure previously unsuspected in solutions. The greatly elongated particles found in a purified preparation of tobacco mosaic virus may be, in part at least, an artefact produced during the course of purification.

Other viruses, isolated from tomato, cucumber, potato and Hyoscyamus show similar optical phe. nomena, but tomato bushy stunt virus differs in that the solutions show no unusual optical properties, but when precipitated isotropic dodecahedral crystals are formed.

Most viruses spread readily from the point of entry throughout the infected plants to give a systematic infection, but in tobacco necrosis the symptoms are restricted to necrotic lesions on the inoculated leaves. Several different viruses and virus strains can cause the symptoms of tobacco necrosis, but on purification they precipitate in various ways.

All viruses so far purified have widely different properties and stabilities and are transmitted in different ways, but all are chemically similar nucleoproteins only varying significantly in their phosphorus and carbohydrate content.

$\mathrm{X}$-ray analyses have shown that the viruses are in a sense double crystalline, and that the virus par. ticles, even when in solution, do not contain any water. It is their chemical simplicity, the regular arrangement of their constituent units and their in. ability to take up water, that most sharply separates viruses from even the simplest known organisms. The intracellular inclusions so characteristic of many virus diseases may prove to be insoluble complexes formed by the virus combining with some constituent of the infected host plant.

The papers were followed by a short discussion, opened by Dr. B. Dyer, who recalled his first meeting with Lawes and Gilbert in 1865, beginning an association with Rothamsted which has lasted to the present day. 